Original Research Article

\title{
Assessment of knowledge, attitude and practice in pharmacovigilance among clinical post graduate students in a teaching hospital, Vizianagaram, Andhra Pradesh, India
}

\author{
Sindhura Nagisetty, Tulasi M. Thotakura*
}

Department of Pharmacology, GITAM Institute of Medical Sciences and Research, Rushikonda, Visakhapatnam, Andhra Pradesh, India

Received: 26 December 2018 Accepted: 29 January 2019

\section{*Correspondence to:}

Dr. Tulasi M. Thotakura, Email:dr.madhu83@gmail.com

Copyright: (C) the author(s), publisher and licensee Medip Academy. This is an openaccess article distributed under the terms of the Creative Commons Attribution NonCommercial License, which permits unrestricted noncommercial use, distribution, and reproduction in any medium, provided the original work is properly cited.

\begin{abstract}
Background: Adverse drug reactions (ADR) are global problem causing morbidity and mortality. Good pharmacovigilance (PV) programme can address this problem. Under reporting of ADR is one of the obstacles for good PV. In order to achieve this, health professionals need to have enough Knowledge, attitude and practice (KAP) of ADR`s. The present study was conducted to assess KAP about PV among post graduate (PG) students.

Methods: A self administered questionnaire validated by Lynn $\mathrm{M}$ consisting of 22 questions covering knowledge, attitude \& practice about PV was distributed among PG students of clinical departments of MIMS College. Answering of the questionnaires was supervised directly. Filled questionnaires were analyzed by using Microsoft Excel spread sheet.

Results: Evaluation showed an average of $52.3 \%$ correct and $47.7 \%$ incorrect knowledge about ADR's and PV.50\% students are not sure regarding occurrence of ADR.90\% students are not been trained upon reporting of ADR`s. Our study found out that PG students have better attitude towards PV, but have improper knowledge \& less awareness about PV. We also found lack of practice among the students.

Conclusions: Imparting knowledge and awareness of PV among the PG students by means of continuous educational intervention can create better practice among PG students.
\end{abstract}

Keywords: Adverse drug reactions, Attitude and practice questionnaires, Knowledge, Lynn M, Pharmacovigilance, Post graduate students

\section{INTRODUCTION}

Drugs are the most common medical interventions widely used in clinical or hospital setting to relieve sufferings. Adverse drug reactions (ADR) are one of the major problems associated with medicines and are recognized hazards of drug therapy.

ADR definition according to WHO is "any noxious, unintended and undesired effect of a drug which occurs at doses used in humans for prophylaxis, diagnosis or therapy of disease, or for the modification of physiological function". 1

ADR's are an important cause of morbidity and mortality and are responsible for a significant number of hospital admissions ranging from $0.3 \%$ to $11 \% .{ }^{2} \mathrm{~A}$ study showed that average cost involved in treating these ADR's was Rs 690/- (US\$ 13.8). ${ }^{3}$ So it is important to identify and treat ADR's as early as possible, as in many instances it is reversible and preventable. This is important to minimize or prevent harm to patients arising from their drugs. 
In the year 2013, India's contribution to WHO - UMC's (Uppsala Monitoring Centre), Sweden- International collaborating centre, global drug safety database (VIGIBASE) was only $2 \% .{ }^{4}$ One of the main reasons for under reporting in India may be lack of knowledge, sensitization towards ADR's and Pharmacovigilance (PV) among health care professionals. ${ }^{5}$

Many studies were done on this assessment of awareness of KAP (Knowledge, attitude and practice) in PV among healthcare professionals. ${ }^{6}$ The primary objective of our study is to evaluate awareness towards PV and ADR reporting among PG (post graduate) students of Maharaja's Institute of Medical Sciences (MIMS), Vizianagaram, Andhra Pradesh. We planned this study with clinical PG students as they are the resident doctors to observe the patient 24 hours while the patient is admitted in the hospital.

\section{METHODS}

It is a non interventional, observational KAP questionnaire study. Prior approval from Institutional Ethics Committee and Heads of respective Clinical departments were obtained. Confidentiality of the student's information were maintained.

\section{Study place}

Maharaja's Institute of Medical sciences, Vizianagaram, Andhra Pradesh.

\section{Duration of study}

Months of August, September 2015. This study was conducted with all PG students of different clinical subjects in 1 st, 2 nd and 3 rd years.

\section{Inclusion criteria}

- All PG students of all the three years who are pursuing their course in clinical subjects.

- All male and female PG students who are willing to participate in this study.

\section{Exclusion criteria}

- All male and female PG students who are not interested to participate in this study.

- All non clinical department PG's are excluded.

- All diploma studying PG students in various clinical subjects are also excluded.

Before conducting study, KAP questionnaire towards PV and ADR's were developed and peer viewed all questions by expert faculties from Department of Pharmacology of our Institute. The questionnaire were semi structured, predesigned, pretested and validated by Lynn M. ${ }^{7}$ This research tool was used by Rajesh et al. ${ }^{8}$ The questionnaire consisted of 22 questions of which 1-12 are based on
Knowledge,13-19 are based on Attitude and 20-22 based on Practice of ADR's and PV. We explained the purpose of the study and distributed the questionnaires. The participants were asked to strike multiple options wherever applicable. They were given 30 minutes to fill them and asked to submit the questionnaires. Out of 102 PG students, 90 PG's returned the answered questionnaires back, 12 PG's declined to participate in the study.

\section{Statistical analysis}

The data were analyzed question wise and their percentage value were calculated by using Microsoft Excel spread sheet in MS office 2007.

\section{RESULTS}

In our study, total PG students enrolled were $(n=90)$ from different clinical departments. Out of them 1st year $(n=31)$, 2nd year $(n=34)$, 3rd year $(n=25)$ students were present when categorised as shown in Table 1. Out of total 90 PG students, there are 48 males and 42 females.

Table 1: Number of post graduate students year wise.

\begin{tabular}{|llll|}
\hline Gender & $\mathbf{1}^{\text {st }}$ year & $2^{\text {nd }}$ year & $3^{\text {rd }}$ year \\
\hline Male & $16(17.7)$ & $21(23.3)$ & $11(12.2)$ \\
\hline Female & $15(16.6)$ & $13(14.4)$ & $14(15.5)$ \\
\hline Total $(\mathrm{n}=90)$ & 31 & 34 & 25 \\
\hline
\end{tabular}

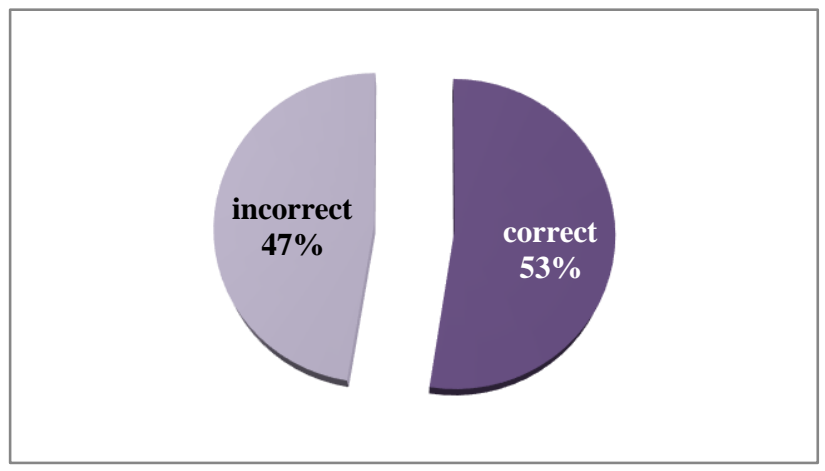

Figure 1: Overall knowledge among all pg`s (\%).

In the present study, $36.6 \%$ only have correct knowledge about the important purpose of PV for identifying the unrecognized ADR's. Only 33.3\% of PG students know about the ADR reporting form in India. 55.5\% students do not know about the location of regional PV centre which is located at Andhra Medical College (AMC), Visakhapatnam. An overall average of correct and incorrect knowledge about ADR's of total PG's was 53\% and $47 \%$ respectively as shown in Figure 1 . Correct knowledge was seen in $55 \%$ of 1 st year, $47 \%$ of 2 nd year and $56 \%$ in 3rd year PG's as shown in Figure 2.

In the present study, the major factors that discourage the doctors of reporting ADR's were difficult to decide about 
the occurrence of an ADR in 6.76\%, non remuneration for reporting in $33.3 \%$, lack of time to report ADR in $55.5 \%$ and a single unreported case may not affect ADR database in $4.44 \%$. An interesting observation is that $31.1 \%$ of the respondents did not think that reporting an ADR is a professional obligation for them. $34.5 \%$ think that establishing an ADR monitoring center in every hospital depends upon the bedsize in a hospital. An overall average of correct attitude about ADR's of total PG's was 53\% as shown in Figure 3. Right attitude was seen in $78 \%$ of 1 st year, $66 \%$ of 2 nd year and $83 \%$ in 3rd year PG's as shown in Figure 4.

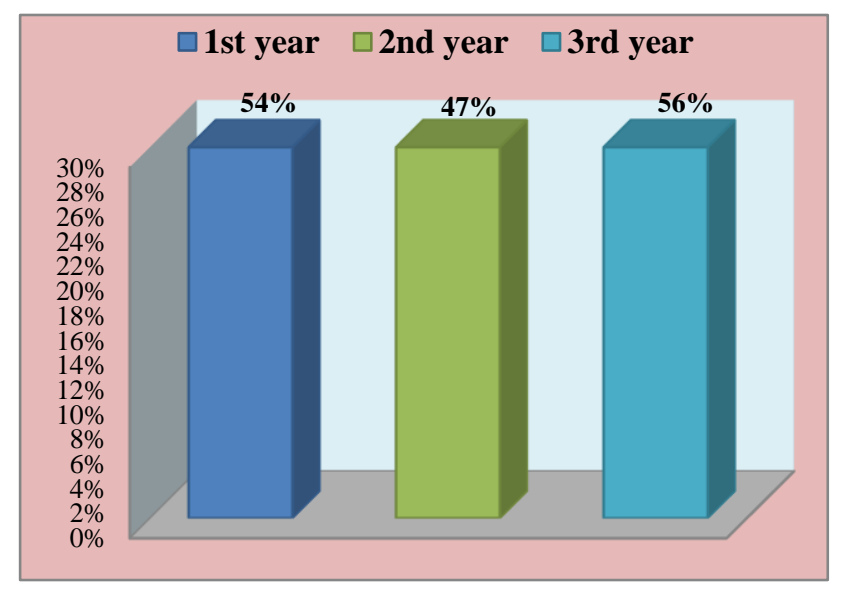

Figure 2: Year wise overall\% of knowledge.

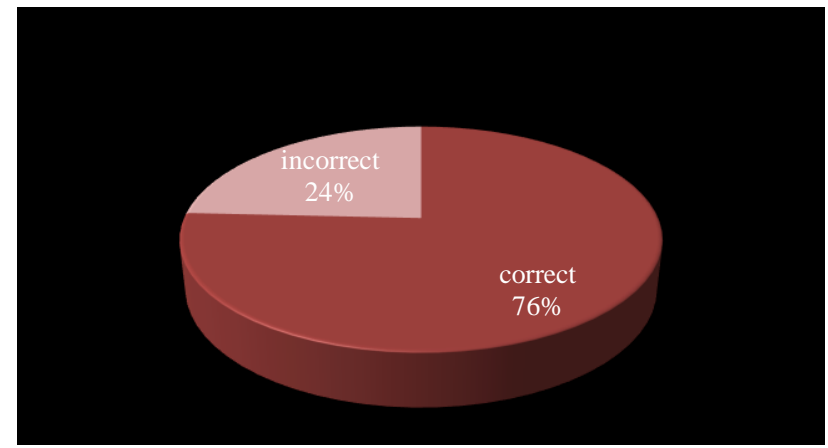

Figure 3: Overall attitude among all pg`s (\%).

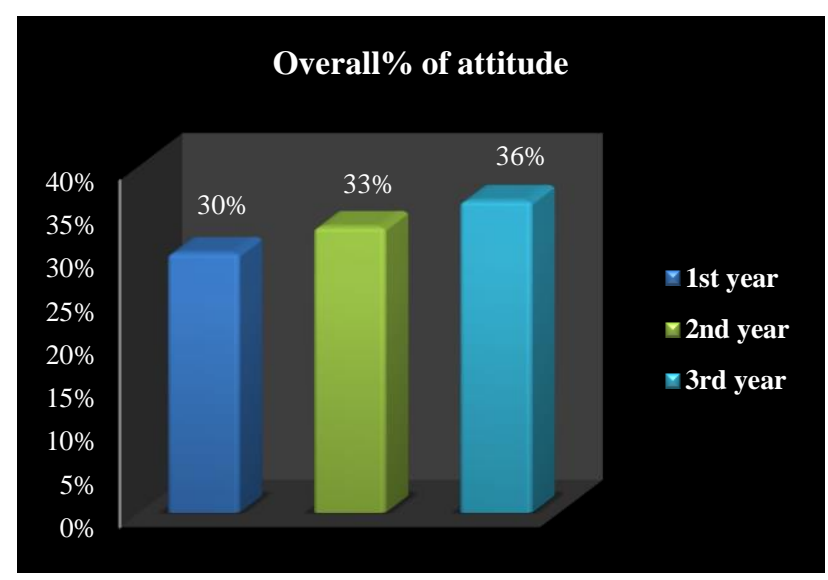

Figure 4: Year wise overall \% of attitude.

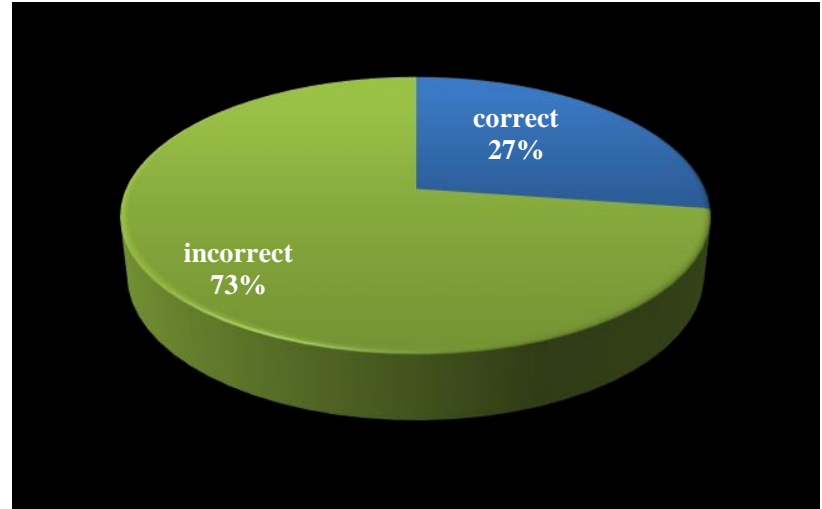

Figure 5: Overall practice among all pg`s.

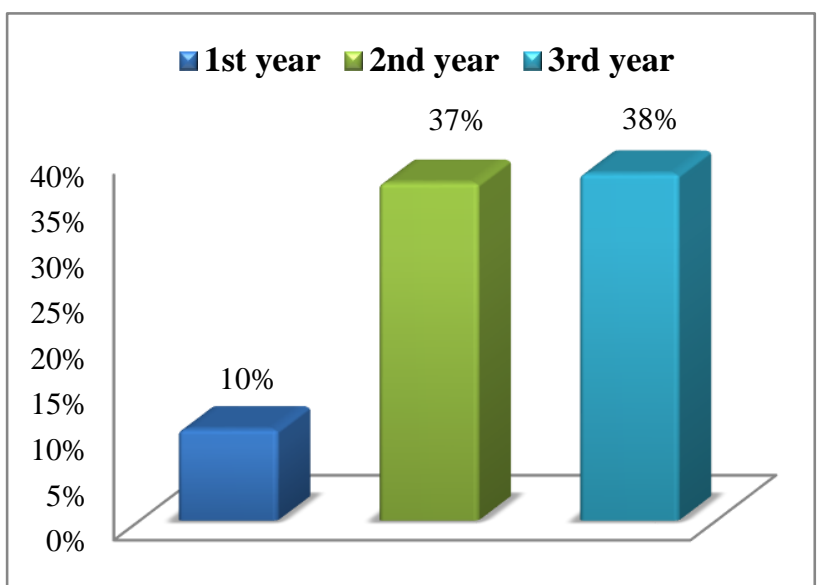

Figure 6: Year wise overall\% of practice.

In the present study $60 \%$ of PG's did not read any article on prevention of ADR's. $66.6 \%$ did not come across with an ADR because it is difficult to decide about the occurence of an ADR. Only $10 \%$ of total PG's were being trained upon reporting an ADR. An overall average of poor practice about ADR's of total PG's was $73 \%$ as shown in Figure 5. Lack of practice was seen in $90 \%$ of 1 st year, $66 \%$ of 2 nd year and $62 \%$ in 3rd year PG's as shown in Figure 6.

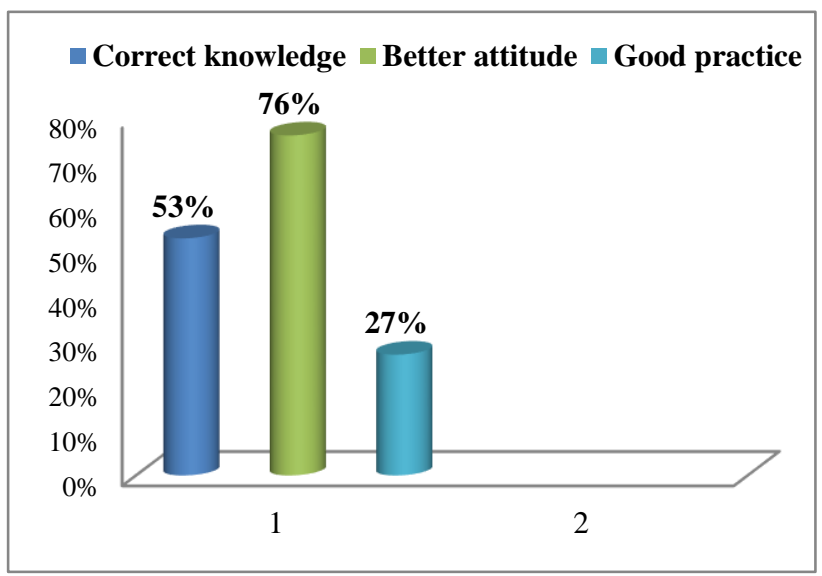

Figure 7: Overall percentage of knowledge, attitude and practice. 


\section{DISCUSSION}

ADR's identification and reporting is an important objective of National PV programme. Spontaneous reporting system is an important method for reporting an ADR. Various factors related with knowledge and attitudes of doctors are attributed to underreporting of ADR's. Most of the previous studies were done on medical professionals towards PV but only few studies have been done among the PG's to evaluate their KAP. ${ }^{9}$ So the present study was done involving PG's.

Khan et al in reported that KAP about ADR of doctors in a teaching hospital was inadequate and require urgent attention not only to improve the rate of spontaneous reporting, but also for enhanced safety of the patients and society at large. ${ }^{10}$ Another study done by Khan showed that deficiencies in knowledge and attitudes appear to be the underlying factor for under reporting by dental practitioners. ${ }^{11}$ A study from Northern India reported that KAP regarding ADR monitoring was low and knowledge scores needed an improvement. ${ }^{12}$ A study from Italy reported that doctors had little information concerning ADR and their reporting systems. ${ }^{13}$ A study from India also identified that awareness about PV and ADR reporting was very low among doctors. ${ }^{14}$

In the present study PG's were aware of various ADR reporting systems that exist for reporting ADR across various countries and also in India. Similar results were seen in a study conducted by Ramesh et al. ${ }^{15}$ The cause for underreporting is lack of time, non remuneration and difficulty in judging an ADR in this study. Chatterjee et al study showed that main reason for underreporting was lack of time and little knowledge about the type of reactions to be preferentially reported. ${ }^{16}$ All 90 PG's think that reporting an ADR is necessary and PV should be taught in detail for all health care professionals. Only $40 \%$ read an article on prevention of ADR and only $10 \%$ have been trained on how to report an ADR.PG's of this study have good knowledge, right attitude but lack practice about PV and ADR reporting. Previous studies suggest that education and creating awareness by CME's according to Kharkar and Bowalekar, training according to study by Chopra et al, increasing awareness through training, workshops, CME's by Pimpalkhute et al, seminars or workshops on PV awareness according to Hardeep et al, would increase ADR reporting. ${ }^{17-20}$

As this is a single centered study with limited number of PG's the results of the study may not be generalized. A multicentric study may provide greater insight about underlying factors for underreporting of an ADR among PG's.

\section{CONCLUSION}

We observed that lack of awareness about ADR reporting system and inadequate training to recognise an ADR as important factors for under reporting an ADR. Imparting the knowledge and awareness of PV among the PG students by means of continuous medical education is required to address this problem. Lack of professional obligation should be considered while designing awareness programs, workshops and training. Inclusion of pharmacovigilance related work in under graduate and PG curriculum will go a long way in success of PvPI.

\section{ACKNOWLEDGEMENTS}

Authors would like to thank Dr. Mamata Bandhyopadhyay, other faculty members and PG's of MIMS for their cooperation throughout the study. We would like to thank Dr. Ramesh B, HOD of department of pharmacology, GIMSR for his cooperation.

Funding: No funding sources

Conflict of interest: None declared

Ethical approval: The study was approved by the Institutional Ethics Committee of MIMS, Nellimarla, India

\section{REFERENCES}

1. World Health Organization. International drug monitoring: The role of national centers. Report of a WHO meeting. World Health Organ Tech Rep Ser. 1972;498:1-25.

2. Sivadasan S. A Study On The Awareness And Attitude Towards Pharmacovigilance And Adverse Drug Reaction Reporting Among Nursing Students In A Private University Malaysia; Int J Pharma Res. 2015;7(1):84-9.

3. Ramesh M, Pandit J, Parthasarathi G. Adverse drug reactions in a south Indian hospital. Their severity and cost involved Pharmacoepidemiol Drug Saf. 2003; 12:687-92.

4. Lihite RJ, Lahkar M. An update on the Pharmacovigilance Programme of India. Front. Pharmacol. 2015;6:194.

5. Tandon VR, Mahajan V, Khajuria V, Gillani Z. Under-Reporting of Adverse Drug Reactions: A Challenge for Pharmacovigilance in India. Indian $\mathbf{J}$ Pharmacol. 2015;47(1):65-71.

6. Goyal M, Bansal M, Yadav S, Grover V, Preetkanwa. To assess the KAP of medical professionals about adverse drug reactions and their reporting in a teaching hospital. Indian $\mathrm{J}$ Clin Pract. 2013;24(3):281-4.

7. Lynn M. Determination and quantification of content validity. Nursing Res.1986;35:382-5.

8. Rajesh R. An Educational Intervention to assess knowledge, attitude and practice of pharmacovigilance among health care professionals in an Indian tertiary care teaching hospital- Int J Curr Pharm Res. 2011;7(1):84-9.

9. Gupta P, Udupa A. Adverse drug reaction reporting and pharmacovigilance: Knowledge, attitudes and perceptions among resident doctors. J Pharm Sci Res. 2011;3:1064-9. 
10. Khan SA, Goyal C, Chandel N, Rafi M. Knowledge, attitudes, and practice of doctors to adverse drug reaction reporting in a teaching hospital in India: An observational study. J Nat SCI Biol Med. 2013;1:191-6.

11. Khan SA, Goyal C, Tonpay SD. A study of knowledge, attitudes, and practice of dental doctors about adverse drug reaction reporting in a teaching hospital in India. Perspect Clin Res. 2015;6(3):144-9.

12. Rehan HS, Vasudev K, Tripathi CD. Adverse drug reaction monitoring: knowledge, attitude and practices of medical students and prescribers. Natl Med J India. 2002;15(1):24-6.

13. Cosentino M, Leoni O, Banfi F, Lecchini S, Frigo G. Attitudes to adverse drug reaction reporting by medical practitioners in a Northern Italian district. Pharmacol Res.1997;35:85-8.

14. Bharathan B, Raju N. A Survey about the Knowledge, Attitude and Practice of Adverse Drug Reaction Reporting Among Doctors in Bangalore City. Sixth Annual Conference of the Society of Pharmacovigilance (India), Kurupanidhi College of Pharmacy, Bangalore, India; 2006;

15. Ramesh M, Parthasarathi G. Adverse Drug Reactions Reporting: Attitudes and Perceptions of Medical Practitioners. Asian J of Pharm Clin Res. 2009;2:104.

16. Chatterjee S, Lyle N, Ghosh S. A survey of the knowledge, attitude and practice of adverse drug reaction reporting by clinicians in eastern India. Drug Saf. 2006;29:641-2.

17. Kharkar M, Bowalekar S. Knowledge, attitude and perception/practices (KAP) of medical practitioners in India towards adverse drug reaction (ADR) reporting. Perspect Clin Res. 2012;3(3):90-4.

18. Chopra D, Wardhan N, Rehan HS. Knowledge, attitude and practices associated with adverse drug reaction reporting amongst doctors in a teaching hospital. Int J Risk Safety Med. 2011;23(4):227-32.

19. Pimpalkhute SA, Jaiswal KM, Sontakke SD, Bajait CS, Gaikwad A. Evaluation of awareness about Pharmacovigilance and adverse drug reaction monitoring in resident doctors of a tertiary care teaching hospital. Indian J Med Sci. 2012;66:55-61.

20. Hardeep, Bajaj JK, Kumar R. A Survey on the Knowledge, Attitude and the Practice of Pharmacovigilance Among the Health Care Professionals in a Teaching Hospital in Northern India. J Clin Diagnos Res. 2013;7(1):97-9.

Cite this article as: Nagisetty $\mathrm{S}$, Thotakura TM. Assessment of knowledge, attitude and practice in pharmacovigilance among clinical post graduate students in a teaching hospital, Vizianagaram, Andhra Pradesh, India. Int J Basic Clin Pharmacol 2019;8:529-33. 